\section{Identifying Opportunities to Promote Water Conservation Practices among Nursery and Greenhouse Growers}

\author{
Laura A. Warner' \\ Department of Agricultural Education and Communication, University of \\ Florida/IFAS, P.O. Box 112060, Gainesville, FL 32611; and University of \\ Florida Center for Landscape Conservation and Ecology
}

Alexa J. Lamm

University of Georgia Department of Agricultural Leadership, Education and Communication and Office of Leadership and Organizational Development, 318 Hoke Smith Building, Athens, GA 30602

\section{Peyton Beattie}

Department of Agricultural Education and Communication, University of Florida/IFAS, P.O. Box 112060, Gainesville, FL 32611; and University of Florida Center for Public Issues Education

Sarah A. White

Department of Plant \& Environmental Sciences, Clemson University, E-143 Poole Agricultural Center, P.O. Box 340319, Clemson, SC 29634

\section{Paul R. Fisher}

Environmental Horticulture Department, University of Florida, P.O. Box 110670, Gainesville, FL 32611-0670

Additional index words. audience analysis, best management practices, irrigation, technology adoption

\begin{abstract}
Nursery and greenhouse growers have an important role to play in conserving water resources. Many technologies are available to help growers conserve water. Yet, within the industry, there may be varying levels of knowledge about a specific strategy, along with inconsistent adoption and continued use. An understanding of these factors can be incorporated into educational programming for this audience. This study evaluated the reported knowledge level of U.S. greenhouse and nursery growers about eight specific water conservation technologies and then explored the rate at which growers had adopted and continued or discontinued their use. Technologies were ranked from high to low adoption rate, beginning with drip irrigation, rainwater capture, water reuse, and microirrigation, followed by soil moisture sensors, climate-based irrigation, subirrigation, and finally an irrigation audit. Overall, greater levels of knowledge corresponded to both greater adoption and continued use of a technology. Other factors, such as economic cost and technical feasibility are undoubtedly important. Findings highlight an opportunity to focus educational programs on the systems-based strategies that are beneficial to growers, but growers are least knowledgeable about to increase adoption of effective water conservation methods that currently have low levels of grower implementation.
\end{abstract}

The availability of adequate irrigation water quantity and quality is an increasingly important issue affecting the green industry. Nursery and greenhouse growers are uniquely positioned to conserve water given the substantial amount they use (Lamm et al., 2017).

Received for publication 23 Jan. 2018. Accepted for publication 29 Apr. 2018.

This material is based on a work that was supported by the National Institute of Food and Agriculture, U.S. Department of Agriculture, under award number 2014-51181-22372.

${ }^{1}$ Corresponding author. E-mail: 1sanagorski@ufl. edu. house growers include precise application of water through appropriate irrigation timing, microirrigation, and reusing runoff water (Mathers et al., 2005). Growers need to have adequate knowledge about water conservation techniques before they will adopt them (Rockwell and Bennett, 2004). The innovationdecision process explains why people will implement an innovation once they know about it, understand how it works, and develop a favorable opinion (Rogers, 2003). Therefore, the decision to implement a water conservation technology needs to be proceeded by creating awareness that the technology exists, knowledge of how it works, and a favorable attitude toward it (Rogers, 2003).

Once a water conservation technique is implemented, a grower will either decide to continue or discontinue using it for several possible reasons during what is known as the confirmation stage of the innovation-decision process (Rogers, 2003). Growers need to continue using conservation innovations to have the greatest impact on water availability. Discontinuance can result when individuals believe that some other innovation is better or when they become dissatisfied with the innovation (Rogers, 2003). An understanding of knowledge levels along with water conservation technique implementation can be used to guide educational strategies, and identifying the rate of discontinuance may be equally as important as implementation (Rogers, 2003).

The research described herein was conducted to identify opportunities to promote water conservation and to inform water conservation education programs targeting U.S. nursery and greenhouse growers. The specific objectives that guided the study were to evaluate grower knowledge level of water conservation technologies, identify those water conservation technologies growers had previously implemented, and establish which water conservation technologies were still in use by U.S. nursery and greenhouse growers.

\section{Materials and Methods}

Study population. Data were collected using a researcher-developed online survey instrument from Jan. 2017 through Apr. 2017. The target population of the study included nursery and greenhouse growers located throughout the United States. We accessed respondents $(N=192)$ through educational program participant lists and an economic electronic mailing list, both maintained by research and extension professionals who work with nursery and greenhouse growers across the United States. The average respondent was male, 55-64 years old, white, and non-Hispanic or Latino. The most common education level was a 4-year college degree. Respondents represented 31 states, and the largest number of growers were from Florida, followed by New York. Fourteen percent of respondents' annual sales were $\$ 10,000,000+$, $20 \%$ were between $\$ 1,000,000$ and $\$ 9,999,000$, $8 \%$ were between $\$ 500,000$ and $\$ 999,999,14 \%$ were between $\$ 100,000$ and $\$ 49,900$, and the most common range (44\%) of respondents' gross annual sales was $\$ 10,000-\$ 99,999$. 
Instrumentation. In consultation with nursery, greenhouse, and extension specialists, we selected eight specific water conservation strategies to evaluate. The technology options surveyed are consistent with a best management practice (BMP) framework for a greenhouse or nursery (FDACS, 2014). These strategies and their definitions were as follows:

1) rainwater capture: collection of rainfall intercepted by the property in a catchment basin or tanks for irrigation use

2) water reuse: capture of excess irrigation water in a catchment basin or tank for reapplication to subsequent crops

3) microirrigation: limited coverage drip and spray emitters that provide precise application to plant roots and the growing substrate

4) drip irrigation: a form of microirrigation where low-flow emitters apply water directly to plant root systems to increase water absorption, provide precise placement, and avoid foliar diseases

5) subirrigation: ebb-and-flood irrigation delivery from below the container, usually combined with a collection tank to hold water and reduce leaching and foliar diseases

6) soil moisture sensors: timing of irrigation based on automated or manual sensors such as tensiometers or dielectric probes that monitor dryness of the growing substrate

7) climate-based irrigation: timing of irrigation using evapotranspiration models and sensors of temperature, relative humidity, rainfall, and/or light

8) irrigation audits: evaluation of irrigation equipment efficiency and BMPs undertaken by an independent irrigation expert or an individual who has had the training to do so

Three parts of the survey pertained to the research objectives reported herein.

Part 1 of the instrument asked growers to indicate their knowledge level for each of the eight water conservation strategies with the question stem: "Please indicate your current level of knowledge as it relates to the following water conservation technologies or practices." Responses were collected along a 5-point Likert-type scale $(1=$ not at all knowledgeable, 2 = slightly knowledgeable, 3 = somewhat knowledgeable, $4=$ moderately knowledgeable, and $5=$ extremely knowledgeable).

Part 2 of the instrument asked growers to indicate which of the eight conservation techniques they had previously implemented ("Please indicate which of the following water conservation technologies or practices you have implemented, if any"). The response format was to check all that apply. Part 3 of the instrument presented only those technologies the respondent indicated they had implemented in part 2 of the instrument and asked growers to indicate which of the conservation techniques they were still using
("Please select those technologies that are still in use at your operation"). This question also used a "check all that apply" format.

We used an expert panel to establish face and construct validity (Field, 2013; Hardesty and Bearden, 2004; Haynes et al., 1995). Face validity was assessed to ensure that the survey instrument was measuring the aspects it was designed to measure (Ary et al., 2014). Construct validity was evaluated to ensure that the survey questions were audience appropriate and were relevant to the objectives of the study (Ary et al., 2014). The panel of experts included people who specialized in water-focused extension programming, agricultural communications, agricultural and biological engineering, and survey methodology. The panel of experts reviewed the instrument for relevance and representativeness of survey items in measuring the variables of interest, and also examined whether the items reflected what they were designed to measure. We made minor changes to the survey instrument based on the review by the expert panel. The research protocol was reviewed and approved by the University of Florida Institutional Review Board before study initiation.

Data analysis. Before analyzing growers' knowledge with the water conservation technologies, we collapsed some of the knowledge response categories to aid in interpretation. We combined responses, so the least amount of knowledge was reflected by two categories (not at all knowledgeable and slightly knowledgeable), a high amount of knowledge was represented by two other categories (moderately knowledgeable and extremely knowledgeable), and a middle category remained (somewhat knowledgeable). After making this adjustment to the knowledge categories, we calculated percentages using the frequency of responses for each of the research objectives.

\section{Results and Discussion}

Growers reported having the highest level of knowledge about rainwater capture, water reuse, and microirrigation (Fig. 1). The lowest level of knowledge was reported for climate-based irrigation and irrigation audits. More growers adopted drip irrigation, rainwater capture, and water reuse than the other water conservation measures (Fig. 2). Climatebased irrigation, subirrigation, and irrigation audits were the least likely to have been implemented by respondents. Among those who had implemented these water conservation measures, microirrigation was the most likely to still be in use, followed by drip irrigation, rainwater capture, and water reuse (Fig. 3). Growers who had implemented irrigation audits, climate-based irrigation, or soil moisture sensors were least likely to continue the use of these technologies. In some cases, it is possible the survey respondents did not have operations that allowed the use of specific technologies. Given the nature of irrigation audits, it is not surprising that they are conducted once and not repeated in some cases. Irrigation audits can be labor intensive and may be perceived as being complicated. However, growers should be encouraged to have their irrigation systems audited on a more regular basis (every year) to ensure continued efficiency of water application, as emitters may clog and wear over time, risers lean, or other factors related to everyday use may have reduced application efficiency.

Rainwater capture and water reuse both reduce the need for external water supply, and in many nurseries, both rainwater and irrigation runoff are collected into an individual catchment basin (Chen et al., 2002). Rainwater capture provides a high-quality water source without the need to pump groundwater from a well or pay for municipal supply. Water capture and reuse reduces runoff of excess irrigation from the property, reducing environmental impact. Knowledge level was high for both rainwater capture and reuse (Fig. 1), with high levels of adoption relative to most other technologies (Fig. 2). Implementation of these technologies requires significant initial capital investment for related drainage and earthworks (Majsztrik et al., 2017), and $83 \%$ or $75 \%$ of adaptors continued the practice of rainwater capture or water reuse, respectively (Fig. 3). The substantial percentage of continued adopters of rainwater capture and water reuse could potentially be due to the monetary investment needed to implement these technologies

Micro-, drip-, and subirrigation technologies are water-efficient irrigation delivery methods which vary in their feasibility depending on the crop type and overall production system. For example, subirrigation is more typically used in covered greenhouse structures on flood benches or floors than in outdoor production, where rainfall is an uncontrolled water source that could lead to drainage problems. By contrast, drip irrigation and other forms of microirrigation (Haman and Izuno, 2003) are suitable for use in both greenhouses and uncovered nurseries. Both knowledge and adoption of micro- and drip irrigation were higher than those for subirrigation (Figs. 1 and 2). Capital investment in drip irrigation was reported by Simonne et al. (2008) at \$1235-\$2964 per hectare for field production. By contrast, costs of subirrigation systems, including materials and installation labor for the irrigation facilities, plumbing, and storage tanks exceeded $\$ 95,000$ for an $1858 \mathrm{~m}^{2}$ greenhouse in 1998 (Uva et al., 2001). Greater economic and technical barriers, therefore, exist to adoption of subirrigation compared with micro or drip irrigation.

Sensor-based and climate-based irrigation technologies support efficient irrigation control decisions, which are becoming increasingly feasible with continuing development of new sensor and control technologies (Lea-Cox et al., 2013; Million and Yeager, 2015). Because sensor-based irrigation control, including wireless sensing and internet-based communication, is newer than some other technologies in the survey, growers may have less knowledge and adoption as indicated in Figs. 1 and 2. These technologies are highly informationbased, requiring a greater level of training 


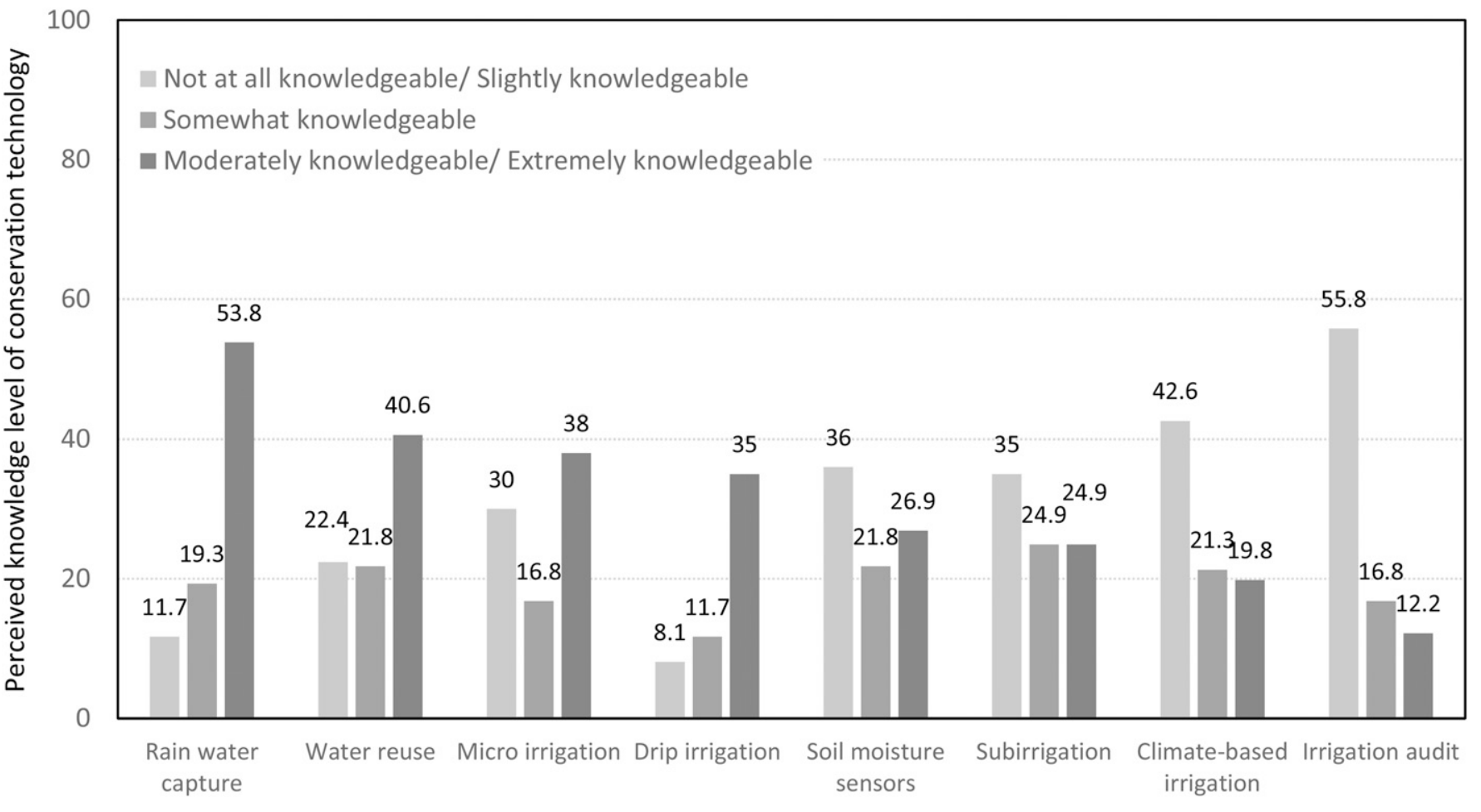

Fig. 1. Reported (perceived) knowledge level of water conservation technologies. Note: Values may not total $100 \%$ because there were respondents that did not respond to every item.

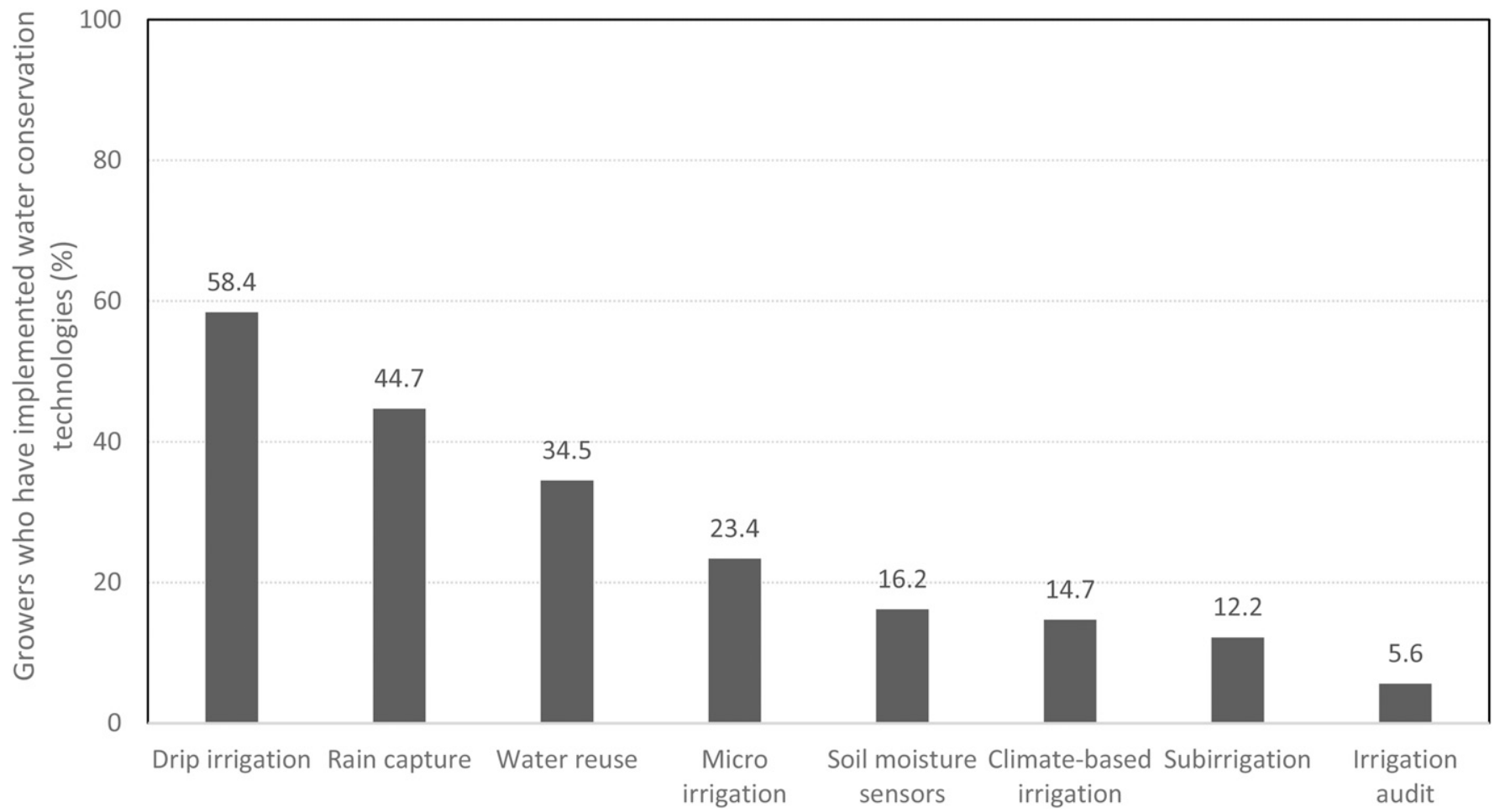

Fig. 2. Water technologies implemented by U.S. nursery and greenhouse growers.

and management input to successfully implement compared with other options surveyed, which may have reduced the continued use (Fig. 3). Lichtenberg et al. (2013) estimated the annual cost of $\$ 3755$ for a soil moisture sensorbased irrigation system in a $1858 \mathrm{~m}^{2}$-greenhouse, resulting in a substantial increase in profitability of Gardenia augusta production within a year because of a shorter crop time. Increased communication of the economic potential of emerging sensor technologies is needed as a precursor to wider adoption.

An irrigation audit is conducted by trained grower staff or a service provided by certified personnel to evaluate irrigation system operation and design and identify opportunities to improve water-use efficiency. Knowledge level and adoption of irrigation audits were low (Fig. 1), despite widespread university extension workshops and bulletins on BMPs, including check lists and methodologies for 


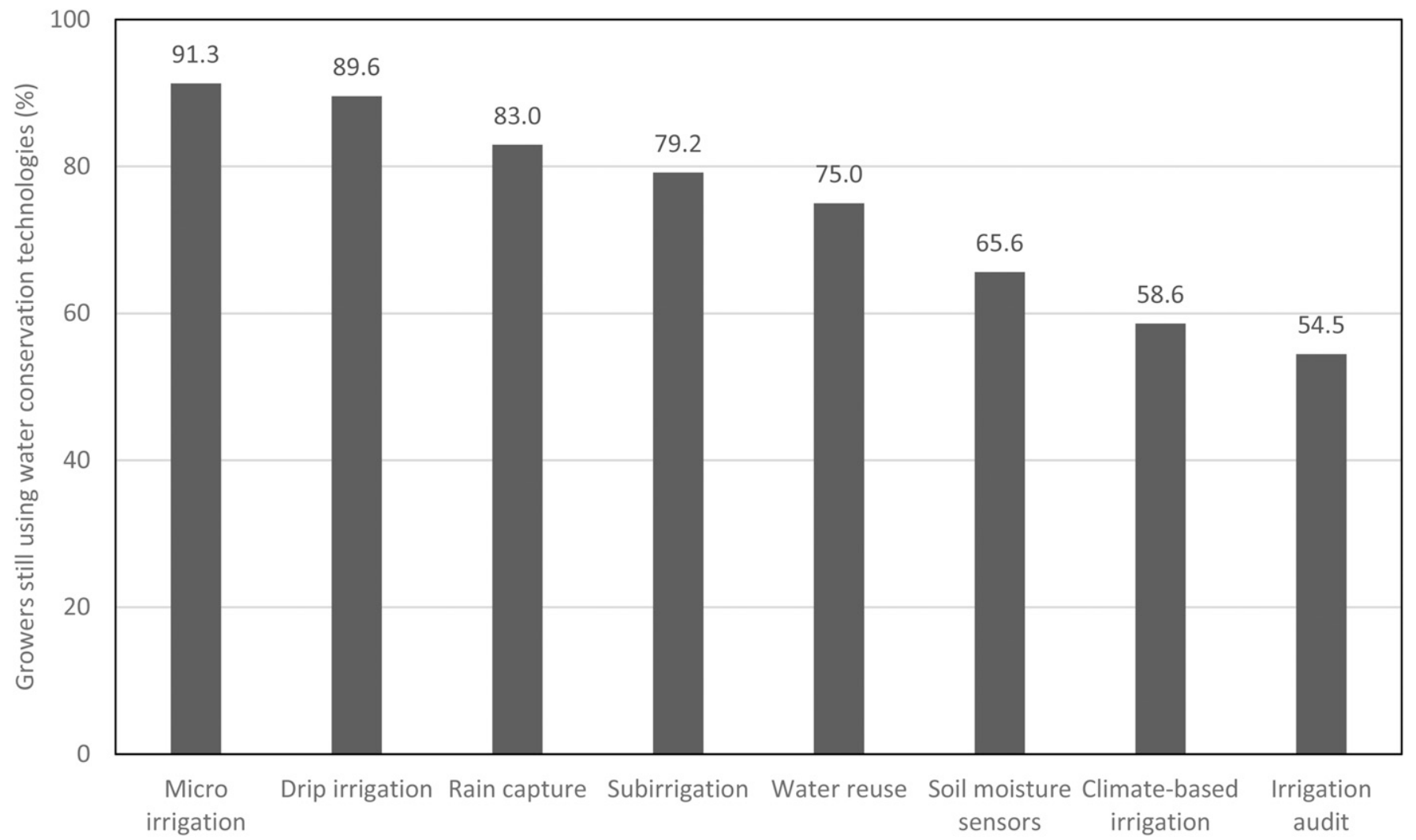

Fig. 3. Water technologies still in use by U.S. nursery and greenhouse growers.

self-auditing of nursery irrigation systems (Yeager, 2013), and subsidized auditing services provided by many water management organizations. The low continued use of an irrigation audit (Fig. 3) is perhaps more difficult to interpret than with other technologies because an audit is a periodic checkup event rather than a continuous irrigation activity. In future studies, it could be beneficial to account for the various types of growers (i.e., operation size, nursery vs. greenhouse, ownership, education, etc.) as well as owner characteristics (especially when the owner and grower are not the same person) and how the type of grower will affect the adoption of these conservation technologies. In addition, future research should examine other factors (i.e., the costs of these conservation strategies, regulations or restrictions, etc.) not investigated here that may influence the adoption of water conserving technologies.

Overall, adoption of water conservation technologies followed a general pattern where more knowledge corresponded with greater likelihood of adoption. The four technologies with which the greatest number of growers report being moderately or extremely knowledgeable were the four most likely to have been implemented at some point. There is some exception to the pattern for drip irrigation in that it was fourth in terms of knowledge level but the most likely to have been implemented, but as noted previously, drip irrigation has a low technical and economic barrier relative to some other technologies.
Given the relationship between knowledge and implementation along with varied levels of knowledge with the conservation technologies, horticultural professionals who educate nursery and greenhouse growers should work to increase knowledge levels that are currently low. There is a definite opportunity to educate growers about systemsbased decision-making strategies, which include climate-based irrigation and irrigation audits. There are also opportunities to educate growers about soil moisture sensors and subirrigation to encourage greater implementation of these technologies when feasible.

At least half of those growers who had implemented any of the eight water conservation technologies were still using them. About nine of 10 growers who implemented either microirrigation or drip irrigation still used these technologies. Only about half of the growers who implemented irrigation audits or climate-based irrigation still reported using them. Similar to initial implementation, growers were more likely to continue using those conservation approaches where they reported greater levels of knowledge. In addition, continuance seems to be related to greater levels of adoption, meaning when greater numbers of growers have adopted an innovation, they are more likely to continue using it. This implies that social support and industry norms contribute to the continued use of water conservation strategies.

Growers who discontinued the use of a water conservation technology likely did so because they were dissatisfied or found another water conservation innovation they believed was better (Rogers, 2003). The former case can be a result of a poor fit between the technology and the adopter or in some cases, the technology never became part of the operations' routine (Rogers, 2003), possibly because of a lack of adequate knowledge. The latter cause of discontinuance can be a result of the many water conservation options emerging today. In these cases, discontinuance does not mean that the growers were not conserving water but were perhaps conserving in other ways.

Although the initial implementation of water conservation technologies is important, people who educate nursery and greenhouse growers should provide support that lasts beyond initial adoption. This support should reinforce the initial decision to implement the technology, troubleshoot any issues that arise, and help growers to incorporate the conservation strategy as a part of their routine. Educators' continued interaction beyond initial adoption can help growers as they decide whether to continue or discontinue the use of a conservation technology based on site-specific constraints and performance (economic and efficacy) assessments. Discontinuance is more common among those who adopt later (Rogers, 2003). Therefore, people who educate nursery and greenhouse growers should particularly target support toward those who may have hesitated to implement a new conservation practice in the first place. Furthermore, they should provide support for continued use of those technologies with which discontinuance is 
more common (soil moisture sensors, climatebased irrigation, and irrigation audits).

The opportunity exists to further explore the relationship between implementation and continued use. It would be beneficial to examine whether discontinuance is a result of dissatisfaction with the conservation strategy or preference for another technology. Future studies should closely examine the specific reasons growers discontinue using a water conservation technology.

\section{Literature Cited}

Ary, D., L.C. Jacobs, C.K. Sorensen, and D.A. Walker. 2014. Introduction to research in education. Wadsworth, Cengage Learning, Belmont, CA.

Beeson, R.C., Jr., M.A. Arnold, T.E. Bilderback, B Bolusky, S. Chandler, H.M. Gramling, J.D. Lea-Cox, J.R. Harris, P.J. Klinger, H.M. Mathers, J.M. Ruter, and T.H. Yeager. 2004. Strategic vision of container nursery irrigation in the next ten years. J. Environ. Hort. 22(2):113-115.

Chen, J., R.C. Beeson, Jr., R.H. Stamps, T.H. Yeager, and L.A. Felter. 2002. Potential of collected stormwater and irrigation runoff for foliage and bedding plant production. Univ. Florida Inst. Food Agr. Sci. Ext. Bul. ENH864.

Dennis, J.H., G.L. Roberto, B.K. Behe, C.R. Hall, C. Yue, and B.L. Campbell. 2010. Sustainable production practices adopted by greenhouse and nursery plant growers. HortScience 45:1232-1237.

Field, A. 2013. Discovering statistics using IBM SPSS statistics. 4th ed. Sage, London, England.

Florida Department of Agriculture and Consumer Services (FDACS). 2014. Water quality/quantity best management practices for Florida nurseries. 26 Oct. 2017. <http://www.freshfromflorida.com/ content/download/37570/848371/nurseryBMPlores.pdf>.

Fulcher, A., A.V. LeBude, J.S. Owen, Jr., S.A. White, and A.R. Beeson. 2016. The next ten years: Strategic vision of water resources for nursery producers. HortTechnology 26:121132.

Haman, D.Z. and F.T. Izuno. 2003. Principles of micro irrigation. Univ. Florida Inst. Food Agr. Sci. Ext. Bul. AE70.

Hardesty, D.M. and W.O. Bearden. 2004. The use of expert judges in scale development: Implications for improving face validity of measures of unobservable constructs. J. Bus. Res. 57 (2):98-107.

Haynes, S.N., D. Richard, and E.S. Kubany. 1995. Content validity in psychological assessment: A functional approach to concepts and methods. Psychol. Assess. 7(3):238-247.

Hodges, A.W., C.R. Hall, B.K. Behe, and J.H. Dennis. 2008. Regional analysis of the U.S. nursery industry. HortScience 43:1807-1812.

Lamm, A.J., L.A. Warner, M.R. Taylor, E.T. Martin, S.A. White, and P. Fisher. 2017 Diffusing water conservation and treatment technologies to nursery and greenhouse growers. J. Intl. Agr. Ext. Educ. 24(1):105-119.

Lea-Cox, J.D., W.L. Bauerle, M.W. van Iersel, G.F. Kantor, T.L. Bauerle, E. Lichtenberg, D.M. King, and L. Crawford. 2013. Advancing wireless sensor networks for irrigation management of ornamental crops: An overview. HortTechnology 23:717-724.

Lichtenberg, E., J. Majsztrik, and M. Saavoss. 2013. Profitability of sensor-based irrigation in greenhouse and nursery crops. HortTechnology 23:770-774.

Majsztrik, J.C., R.T. Fernandez, P.R. Fisher, D.R. Hitchcock, J. Lea-Cox, J.S. Owen, Jr., L.R. Oki, and S.A. White. 2017. Water use and treatment in containerized specialty crop production: A review. Water, Air, and Soil Pollut. 228:151.

Mathers, H.M., T. Yaeger, and L.T. Case. 2005. Improving irrigation water use in container nurseries. HortTechnology 15:8-12.

Million, J.B. and T.H. Yeager. 2015. CIRRIG: Weather-based irrigation management program for container nurseries. HortTechnology 25:528-535.

Rockwell, K. and C. Bennett. 2004. Targeting outcomes of programs: A hierarchy for targeting outcomes and evaluating their achievement. Faculty Publications: Agricultural Leadership, Education \& Communication Department. 26 Oct. 2017. <http://digitalcommons.unl.edu/ aglecfacpub/48/>.

Rogers, E.M. 2003. Diffusion of innovations. 5th ed. Free Press, New York, NY.

Simonne, E., R. Hochmuth, J. Breman, W. Lamont, D. Treadwell, and A. Gazula. 2008. Drip-irrigation systems for small conventional vegetable farms and organic vegetable farms. Univ. Florida Inst. Food Agr. Sci. Ext. Bul. HS1144.

Uva, W.L., T.C. Weiler, and R.A. Milligan. 2001. Economic analysis of adopting zero runoff subirrigation systems in greenhouse operations in the northeast and north central United States. HortScience 36:167-173.

Yeager, T.H. 2013. Nursery irrigation system checklist. Univ. Florida Inst. Food Agr. Sci. Ext. Bul. ENH1208. 